\title{
BMJ Open Impact of integrated health system changes, accelerated due to an earthquake, on emergency department attendances and acute admissions: a Bayesian change-point analysis
}

\author{
Philip J Schluter, ${ }^{1,2}$ Greg J Hamilton, ${ }^{3}$ Joanne M Deely, ${ }^{4}$ Michael W Ardagh ${ }^{5,6}$
}

To cite: Schluter PJ, Hamilton GJ, Deely JM, et al. Impact of integrated health system changes, accelerated due to an earthquake, on emergency department attendances and acute admissions: a Bayesian change-point analysis. BMJ Open 2016;6:e010709. doi:10.1136/bmjopen-2015010709

- Prepublication history for this paper is available online. To view these files please visit the journal online (http://dx.doi.org/10.1136/ bmjopen-2015-010709).

Received 30 November 2015 Revised 10 April 2016 Accepted 14 April 2016

CrossMark

For numbered affiliations see end of article.

\section{Correspondence to}

Professor Philip J Schluter; philip.schluter@canterbury. ac.nz

\section{ABSTRACT}

Objective: To chart emergency department (ED) attendance and acute admission following a devastating earthquake in 2011 which lead to Canterbury's rapidly accelerated integrated health system transformations.

Design: Interrupted time series analysis, modelling using Bayesian change-point methods, of ED attendance and acute admission rates over the 20082014 period.

Setting: ED department within the Canterbury District Health Board; with comparison to two other district health boards unaffected by the earthquake within New Zealand.

Participants: Canterbury's health system services 500 000 people, with around 85000 ED attendances and 37000 acute admissions per annum.

Main outcome measures: De-seasoned standardised population ED attendance and acute admission rates overall, and stratified by age and sex, compared before and after the earthquake.

Results: Analyses revealed five global patterns: (1) postearthquake, there was a sudden and persisting decrease in the proportion of the population attending the ED; (2) the growth rate of ED attendances per head of population did not change between the preearthquake and postearthquake periods; (3) postearthquake, there was a sudden and persisting decrease in the proportion of the population admitted to hospital; (4) the growth rate of hospital admissions per head of the population declined between preearthquake and postearthquake periods and (5) the most dramatic reduction in hospital admissions growth after the earthquake occurred among those aged 65+ years. Extrapolating from the projected and fitted deseasoned rates for December 2014, 676 (16.8\%) of 4035 projected hospital admissions were avoided.

Conclusions: While both necessarily and opportunistically accelerated, Canterbury's integrated health systems transformations have resulted in a dramatic and sustained reduction in ED attendances and acute hospital admissions. This natural intervention experiment, triggered by an earthquake, demonstrated that integrated health systems with high

\section{Strengths and limitations of this study}

- This is the first general population study that sought to provide a longitudinal assessment of emergency department attendance and acute admission rate changes following a rapid healthcare system reorientation.

- Novel interrupted time series analyses, modelled using Bayesian change-point methods, were employed to investigate sudden and long-term changes in attendance and admission rates prior to and following a devastating earthquake.

- By itself, a limitation of this natural intervention experiment analysis is the potential difficulty in separating effect attribution due to the earthquake, the system reorientation or other drivers.

- The geographically localised perimeter of this study, together with its focus on only two key variables, may fail to capture the full scope of population health seeking behaviour changes resulting from the integrated health system reorientation and may limit its generalisability to other jurisdictions.

quality out-of-hospital care models are likely to successfully curb growth in acute hospital demand, nationally and internationally.

\section{INTRODUCTION}

Acute admissions from emergency departments (EDs) are costly and often preventable, yet they have been rapidly growing in many countries. ${ }^{1-3}$ A continuing unabated increase in acute admissions potentially threatens the safe delivery of national public health services. ${ }^{1}{ }^{4}{ }^{5}$ In the UK, a series of publications concerned about the effect of rising hospital admissions have characterised hospitals as being 'on the edge', ${ }^{6}$ that admissions are 'out of control', ', and that an 


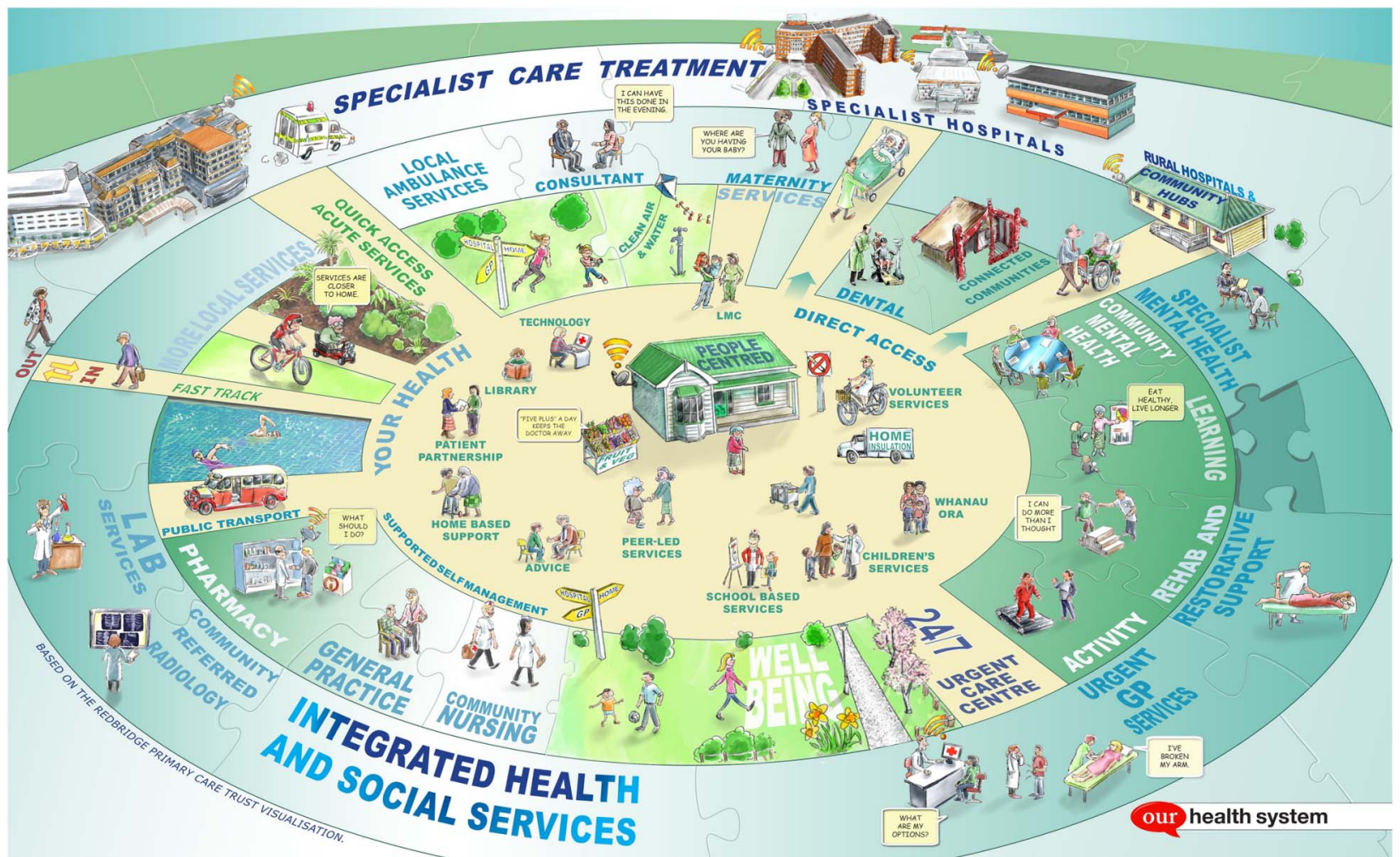

Figure 1 Canterbury integrated health system vision. (Reproduced from Gullery and Hamilton, ${ }^{5}$ copyright 2015 Royal College of Physicians. Reproduced with permission.)

urgent 'call to action, is needed. While these publications are perhaps provocative, 'business as usual' models of healthcare delivery will not be viable in the future. Similar sustainability concerns have been raised in New Zealand, ${ }^{59}$ and a reorientation of the country's healthcare systems called for-although it is recognised that there is no one panacea. ${ }^{10}$ Disease prevention is seen as a key solution, as is harnessing technological, social and other innovations. ${ }^{8}$ Proactive management of people with long-term conditions, together with multiple coordinated strategies underpinned by an integrated information system have also been mooted as among the key strategies to reduce ED demand. ${ }^{11}{ }^{12}$ However, there is mounting recognition and consensus that integrated, cross-sector solutions are fundamental in redressing the sustainability issues plaguing our health systems, ${ }^{5} 8101113$ although their direct effects on hospital admission rates is not yet understood. ${ }^{14}$

The Canterbury District Health Board (CDHB) - the organisation charged with planning, managing, providing and purchasing health services to meet the needs of the population within the greater Christchurch regionin 2008 began implementing a significant transformation to integrated services. ${ }^{5}$ Among the primary motivations for this rescoping was to decrease fragmentation of services, dismantle professional silos, reduce escalating and unsustainable clinical and resource pressures on the Canterbury health system, ensure services were arranged more effectively and efficiently, and ultimately, to improve the health of its population. ${ }^{5}$ The vision for the integrated health system centred around enabling people to stay in their own homes, with an interconnected structure supporting them to live well and take greater responsibility for their own health; figure 1. It focused on integrating primary healthcare and other community sectors in managing patients. ${ }^{5} 13$ This wholesystem approach was supported by several key service model enablers, including the Acute Demand Management Service (ADMS, a hospital avoidance programme) and the Community Rehabilitation Enhancement Support Team (CREST, a wrap-around, home-based rehabilitation programme), and system enablers, including 'HealthPathways' and the Canterbury Initiative (primary care doctors and hospitalbased specialists developing and agreeing to primary care management and referral pathways). ${ }^{5}{ }^{15}$ ADMS is founded on primary care doctors managing patients in their own homes and communities where it is safe to do so. ${ }^{5} 13$ Primary care teams, supported by mobile acute nursing services, community observation beds and rapid diagnostic services, are enabled to 'do whatever it takes' ${ }^{15}{ }^{16}$ 'HealthPathways' provides guidance to primary care teams and includes system-wide agreed ambulance diversion protocols for patients to be managed in primary care practice or urgent care centres including a $24 \mathrm{~h}$ surgery where appropriate.

On Tuesday, 22 February 2011, at 1251 h New Zealand Standard Time, a shallow violent $6.3 \mathrm{Mw}$ earthquake with 
epicentre $10 \mathrm{~km}$ southeast of Christchurch struck. ${ }^{17} 18$ Damage and destruction was extensive; ${ }^{17}{ }^{19}$ a state of national emergency declared,,$^{20}$ and 185 deaths and over 6500 injuries resulted. ${ }^{18}{ }^{21}$ Immediately after the earthquake there was considerable burden placed on Christchurch's seven hospitals. However, Christchurch Hospital is the only acute hospital within the region that has an ED, an intensive care unit, and a full range of tertiary hospital surgical and medical services. ${ }^{22}$ It was partially compromised by earthquake damage, and several non-acute hospitals temporarily provided emergency care. ${ }^{18}$ Damage to roads, bridges and other infrastructure isolated the east of the city from Christchurch Hospital, leaving primary care practitioners in these suburbs to manage many casualties. ${ }^{18}$ Earthquake damage resulted in the loss of 106 acute hospital beds, 635 aged residential care beds, 19 community pharmacies, five primary care practices, and displaced many small non-governmental organisations from the central city. Owing to the infrastructure damage and medical demands in the ensuing weeks and months following the earthquake, it was both necessary and an opportunity for the CDHB to accelerate transformational changes and implement new initiatives. One major strategy included the escalation of ADMS, with a deliberate intent in reducing ED attendances and hospital admissions. ${ }^{523}$

This descriptive epidemiological study assessed the impact of an integrated health system on ED attendances and acute admissions at Christchurch Hospital, New Zealand, before and after a major earthquake.

\section{METHODS}

Using routinely collected data between 2008 and 2014, we compared acute admission rates following Christchurch Hospital's ED attendances before and after the earthquake with data from Waitemata DHB (WDHB) and Auckland DHB (ADHB) that serve the population of greater Auckland. WDHB and ADHB are in the North Island of New Zealand and were geologically unaffected by the earthquake. The WDHB was selected because it has a demographically similar population to that of the CDHB, but it does not have a tertiary hospital. ADHB was chosen because it does have such a hospital.

\section{Design}

An interrupted time series design, modelling using Bayesian change-point methods, of ED attendance and acute admission rates over the 2008-2014 period.

\section{Target population}

All patient ED attendances and acute admissions within the CDHB; with comparison to patients within the WDHB and ADHB jurisdictions.

\section{Procedure}

Monthly aggregated and anonymised ED attendance and admission volume data were provided from CDHB,
WDHB and ADHB regions over the 2008-2014 period. These data were stratified by sex (male, female) and age groupings (each spanning 5 years). Similarly, stratified annual population projections were obtained from Statistics New Zealand for these DHBs. ${ }^{24}$ Following the 2013 Census, the 2013 and 2014 annual population projections were amended, accounting for evacuations and movement.

\section{Patient involvement}

No patients were involved in setting the research question or the outcome measures, nor were they involved in the design and implementation of the study. There are no plans to involve patients in dissemination.

\section{Statistical analyses}

Utilising the annualised population projections, standardised monthly attendance and admission rates (per 1000 people) were calculated. Scatter plots and superimposed lowess curves (non-parametric mean estimate function) were used to ascertain patterns. Time series analysis of the CDHB data employed Bayesian methods, in which series were partitioned into constant, trend and seasonal components; together with allowing for a disconnected change-point mechanism to account for any significant interruption caused by the earthquake..$^{25}$ Seasonal adjustment was modelled by assigning a categorical indicator variable for each month. A disconnected change-point model allows for a piecewise mean and slope shift within the time series to be statistically detected and assigned. Separate models were run for attendance and admission rate series (where the change point was estimated from the data and compared to the actual earthquake date), and for these data partitioned by sex and age groups (where the change point was set to the earthquake date). Here, monthly data were assigned an integer value from 1 (January 2008) to 84 (December 2014). Standardised rates were assumed to be normally distributed. Non-informative priors were employed and Markov chain Monte Carlo methods utilised two parallel chains, each with simulation size $\mathrm{n}=100000$ after a burn-in period of 5000 iterations. The Gelman-Rubin statistic and visual plots were used to assess model convergence and stability; and residual distribution and autocorrelation checks were conducted. In comparing rates, posterior probabilities (pp) were employed. Estimated $\mathrm{pp}<0.025$ and $\mathrm{pp}>0.975$ were deemed to be statistically significant, and $95 \%$ credible regions (CRs) were derived by using the 2.5 and 97.5 centiles of the posterior distribution. A pp $>0.975$ implies that the pre-earthquake rate was importantly higher than the postearthquake rate; $p p<0.025$ implies that the pre-earthquake rate was importantly lower than the postearthquake rate; and $0.025 \leq \mathrm{pp} \leq 0.975$ implies that there was no important change in rates between periods. All statistical analyses were conducted in WinBUGS V.1.4.3, ${ }^{26}$ and graphs were drawn in Stata V.14.1 (StataCorp, College Station, USA). 
Table 1 Total population projections for CDHB, WDHB, and ADHB regions estimated by Statistics New Zealand and total ED attendances and hospital admissions from 2008 to 2014

\begin{tabular}{|c|c|c|c|c|c|c|c|c|c|}
\hline \multirow[b]{2}{*}{ Year } & \multicolumn{3}{|l|}{ CDHB } & \multicolumn{3}{|l|}{ WDHB } & \multicolumn{3}{|l|}{ ADHB } \\
\hline & Pop $^{n}$ & Attendances & Admissions & Pop $^{n}$ & Attendances & Admissions & Pop $^{n}$ & Attendances & Admissions \\
\hline 2008 & 495940 & 76550 & 34834 & 520950 & 79010 & 47512 & 438130 & 83704 & 53769 \\
\hline 2009 & 502040 & 81178 & 35784 & 528720 & 77589 & 47547 & 444190 & 87925 & 56162 \\
\hline 2010 & 508250 & 86938 & 39443 & 537480 & 88415 & 52051 & 450290 & 85075 & 53520 \\
\hline 2011 & 502780 & 78900 & 35875 & 546200 & 98567 & 56285 & 456640 & 92539 & 54694 \\
\hline 2012 & 503460 & 82784 & 36316 & 553080 & 102540 & 59186 & 461230 & 95534 & 56984 \\
\hline $2013^{*}$ & 504220 & 88031 & 38315 & 552770 & 105769 & 60862 & 460450 & 98300 & 60720 \\
\hline $2014^{*}$ & 515040 & 92435 & 39180 & 562680 & 110835 & 64270 & 469580 & 102555 & 61701 \\
\hline
\end{tabular}

*Updated population estimates, derived from the 2013 New Zealand Census.

ADHB, Auckland District Health Board; CDHB, Canterbury District Health Board; ED, emergency department; WDHB, Waitemata District Health Board.

\section{RESULTS}

\section{Demographics}

Over the study period, the estimated CDHB population increased by $19100(3.9 \%)$ people; substantially less than that estimated for the WDHB and ADHB jurisdictions of $41730(8.0 \%)$ and 31450 (7.2\%) people, respectively (table 1 ). The annual $\mathrm{ED}$ attendance numbers for the CDHB, WDHB and ADHBs also increased by 15885 (20.8\%), 31825 (40.3\%) and 18851 (22.5\%) people, respectively; as did acute admission numbers by $4346(12.5 \%), 16758(35.3 \%)$ and 7932 (14.8\%) people, respectively. Annual CDHB population projections by sex and age groups appear in table 2 . Within the CDHB region, small but important demographic shifts in the distribution of sex and age distributions was discernible over time-with relatively more male residents and adults aged 65+ years, and relatively fewer children aged $0-14$ years.

Figure 2 presents scatter plots of observed standardised monthly ED attendance rates and acute admission rates per 1000 people, together with superimposed lowess curves for the three DHBs. Unlike that observed within the WDHB and ADHB jurisdictions, a clear interrupted pattern change is visible in the scatterplot distribution and superimposed lowess curves before and after the 22 February 2011 earthquake (denoted by the vertical line) for ED attendance and acute admission rates within the $\mathrm{CDHB}$.

\section{ED attendance rates}

Analysis of the observed CDHB standardised monthly $\mathrm{ED}$ attendance rates revealed significant intercept, trend and monthly seasonal components (figure 3). A change point was detected at study period month 38.4 (95\% CR 37.2-39.0). This CR includes the value 38.8 which corresponds to 22 February 2011-the date of the earthquake. At the detected change point, the estimated deseasoned ED monthly attendance rate fell from 14.7/ 1000 people to 12.7 , a decrease that was significant ( $p p>0.999)$ and dramatic (table 3). Also notable in table 3 is the lack of change in the deseasoned growth rate in ED attendances between the pre-earthquake and postearthquake periods $(\mathrm{pp}=0.36)$. These patterns, together with expected postearthquake ED attendance rates extrapolated from pre-earthquake estimates, are also illustrated in figure 3. Residual analyses revealed one outlying observation (February 2011), a unimodal but skewed distribution (Shapiro-Wilk's test, $\mathrm{p}=0.003$ ), and evidence of positive autocorrelation (Durbin-Watson d-statistic=1.12). No other issues were noted.

Table 2 Population projections by sex and age categories for the CDHB region estimated by Statistics New Zealand from 2008 to 2014

\begin{tabular}{|c|c|c|c|c|c|c|c|c|c|c|c|c|}
\hline \multirow[b]{3}{*}{ Year } & \multicolumn{4}{|l|}{ Sex } & \multicolumn{8}{|c|}{ Age (years) } \\
\hline & \multicolumn{2}{|l|}{ Females } & \multicolumn{2}{|l|}{ Males } & \multicolumn{2}{|c|}{$0-14$} & \multicolumn{2}{|l|}{$15-34$} & \multicolumn{2}{|l|}{$35-64$} & \multicolumn{2}{|l|}{$65+$} \\
\hline & Pop $^{n}$ & $(\%)$ & Pop $^{n}$ & (\%) & Pop $^{n}$ & (\%) & Pop $^{n}$ & (\%) & Pop $^{n}$ & (\%) & Pop $^{n}$ & (\%) \\
\hline 2008 & 252450 & (50.9) & 243490 & (49.1) & 94030 & (19.0) & 133860 & (27.0) & 200290 & (40.4) & 67760 & (13.7) \\
\hline 2009 & 255150 & (50.8) & 246890 & (49.2) & 94230 & (18.8) & 134800 & (26.9) & 203360 & (40.5) & 69650 & (13.9) \\
\hline 2010 & 257960 & (50.8) & 250290 & $(49.2)$ & 94690 & (18.6) & 135720 & (26.7) & 206020 & (40.5) & 71820 & (14.1) \\
\hline 2011 & 254840 & (50.7) & 247940 & (49.3) & 92700 & (18.4) & 133780 & (26.6) & 203450 & (40.5) & 72850 & (14.5) \\
\hline 2012 & 254900 & (50.6) & 248560 & (49.4) & 91810 & (18.2) & 133380 & (26.5) & 202640 & $(40.2)$ & 75630 & (15.0) \\
\hline $2013^{*}$ & 253570 & (50.3) & 250650 & (49.7) & 94930 & (18.8) & 132830 & (26.3) & 202510 & (40.2) & 73950 & (14.7) \\
\hline $2014^{\star}$ & 258850 & (50.3) & 256190 & (49.7) & 95520 & (18.5) & 137950 & (26.8) & 204520 & (39.7) & 77050 & (15.0) \\
\hline
\end{tabular}

*Updated estimates, derived from the 2013 New Zealand Census.

CDHB, Canterbury District Health Board. 

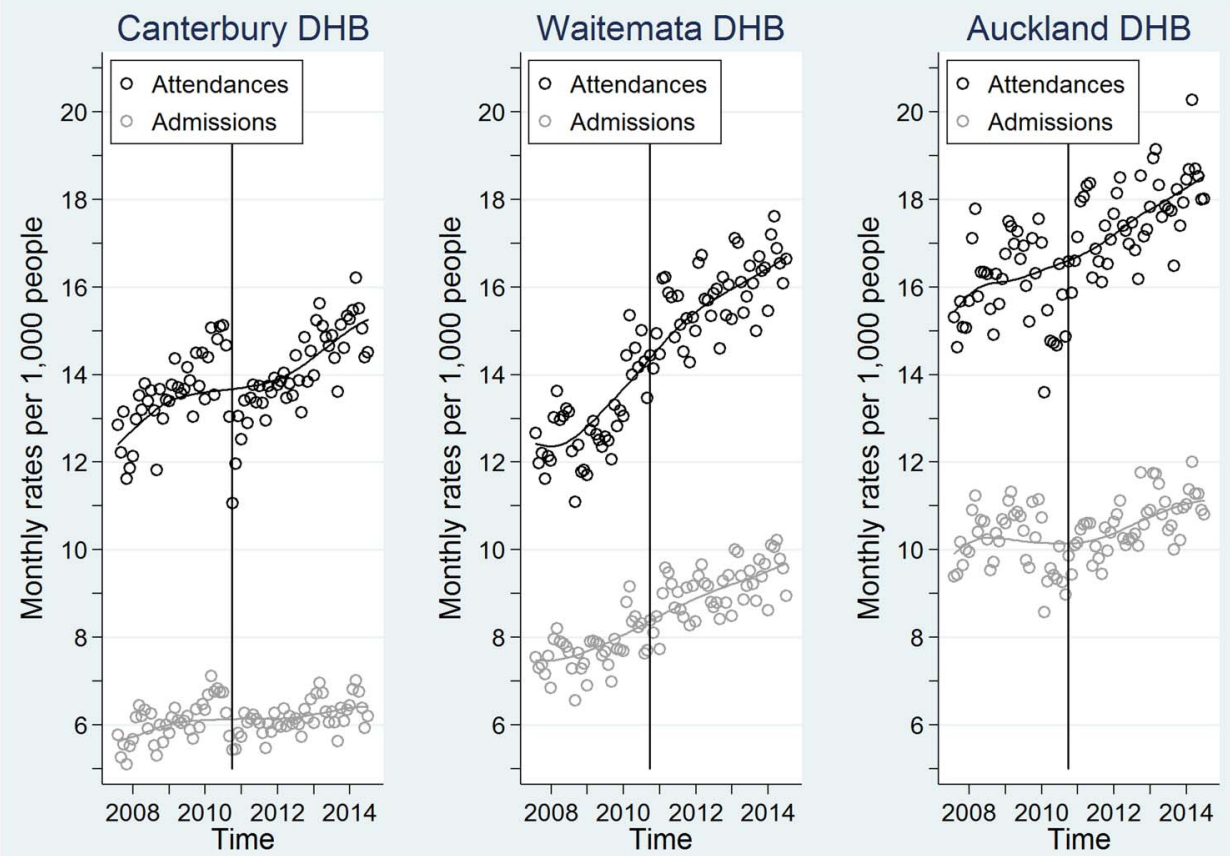

Figure 2 Scatter plots of observed standardised monthly ED attendance rates and acute hospital admissions rates per 1000 people, together with superimposed lowess curves (non-parametric mean estimate function) for the CDHB, WDHB and ADHB between 2008 and 2014. The vertical line denotes the time of the 22 February 2011 earthquake. ADHB, Auckland District Health Board; CDHB, Canterbury District Health Board; WDHB, Waitemata District Health Board.

Fixing the change point to 38.8 and partitioning the data by sex, the Bayesian model yielded estimates of deseasoned rates of ED attendances at the change point that significantly decreased for females and males (table 3). However, there was no significant difference in the monthly increase in deseasoned attendance rates between pre-earthquake and postearthquake periods for

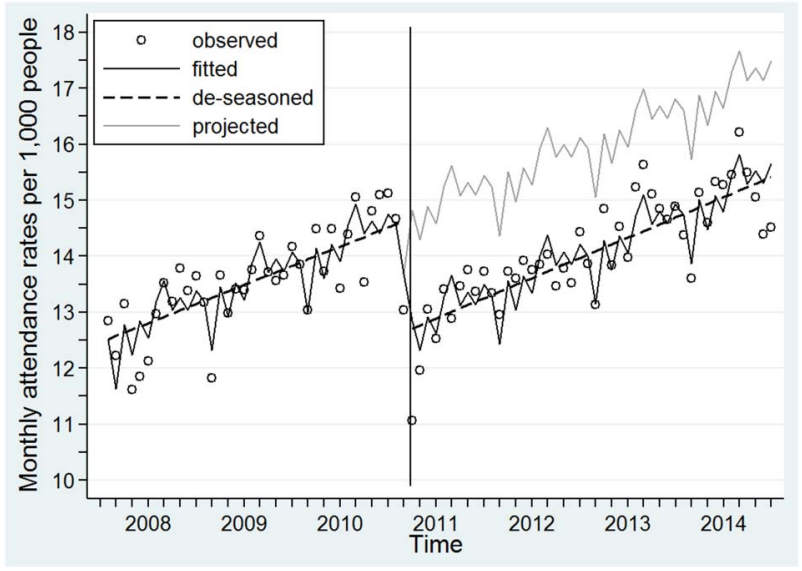

Figure 3 Scatter plots of observed CDHB standardised monthly ED attendance rates per 1000 people (hollow circles), together with a superimposed fitted lined from the full time-series model (solid line), the estimated deseasoned trend line (heavy dashed straight line) and the extrapolated projected line (grey line). The vertical line denotes the time of the 22 February 2011 earthquake. CDHB, Canterbury District Health Board. either sex. When comparing males and females at the change point, males had significantly higher rates of ED attendance than females pre-earthquake ( $p p>0.999)$ and postearthquake ( $p p>0.999)$. However, the monthly increase in attendance rates was not significantly different between females and males either in the period before $(\mathrm{pp}=0.89)$ or after $(\mathrm{pp}=0.78)$ the February earthquake. Repeating the Bayesian analyses on ED attendance data partitioned by age groups yielded generally similar findings. Significant decreases in the deseasoned ED attendances rates were seen across all age groups at the time of the earthquake (all pp $>0.999$ ). Deseasoned monthly increases in ED attendance rates for the $0-14,35-64$ and $65+$ years age groups did not significantly change between pre-earthquake and postearthquake periods. However, for the 15-34 years age group, a significant rise in this rate was observed in the postearthquake period compared with the preearthquake period (table 3 ).

\section{Hospital admissions rates}

Significant intercept, trend and monthly seasonal components were also evident in the analysis of the observed CDHB standardised monthly acute hospital admissions rates (figure 4). For this series, a change point was detected at study period month 38.2 (95\% CR 37.139.0), with the CR again overlapping with the earthquake date. At this detected change point, the estimated deseasoned monthly acute admissions rate significantly fell from $6.59 / 1000$ people to 5.83 , pp $>0.999$. However, 

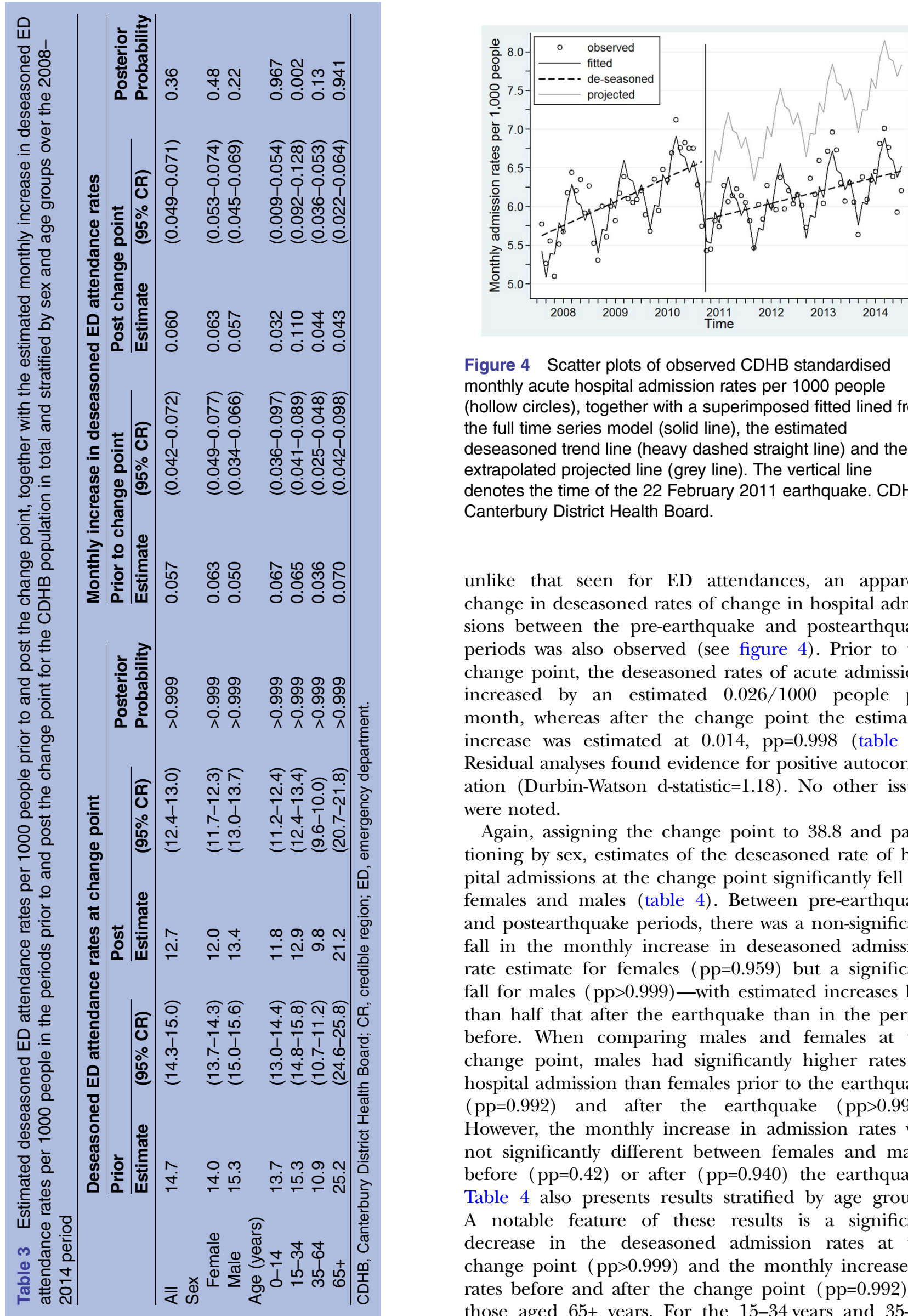

Figure 4 Scatter plots of observed CDHB standardised monthly acute hospital admission rates per 1000 people (hollow circles), together with a superimposed fitted lined from the full time series model (solid line), the estimated deseasoned trend line (heavy dashed straight line) and the extrapolated projected line (grey line). The vertical line denotes the time of the 22 February 2011 earthquake. CDHB, Canterbury District Health Board.

unlike that seen for ED attendances, an apparent change in deseasoned rates of change in hospital admissions between the pre-earthquake and postearthquake periods was also observed (see figure 4). Prior to the change point, the deseasoned rates of acute admissions increased by an estimated $0.026 / 1000$ people per month, whereas after the change point the estimated increase was estimated at $0.014, \mathrm{pp}=0.998$ (table 4). Residual analyses found evidence for positive autocorrelation (Durbin-Watson d-statistic=1.18). No other issues were noted.

Again, assigning the change point to 38.8 and partitioning by sex, estimates of the deseasoned rate of hospital admissions at the change point significantly fell for females and males (table 4). Between pre-earthquake and postearthquake periods, there was a non-significant fall in the monthly increase in deseasoned admission rate estimate for females $(\mathrm{pp}=0.959)$ but a significant fall for males ( $p p>0.999)$-with estimated increases less than half that after the earthquake than in the period before. When comparing males and females at the change point, males had significantly higher rates of hospital admission than females prior to the earthquake $(\mathrm{pp}=0.992)$ and after the earthquake ( $\mathrm{pp}>0.999)$. However, the monthly increase in admission rates was not significantly different between females and males before $(p p=0.42)$ or after $(p p=0.940)$ the earthquake. Table 4 also presents results stratified by age groups. A notable feature of these results is a significant decrease in the deseasoned admission rates at the change point $(p p>0.999)$ and the monthly increase in rates before and after the change point $(\mathrm{pp}=0.992)$ of those aged 65+ years. For the 15-34 years and 35-64 


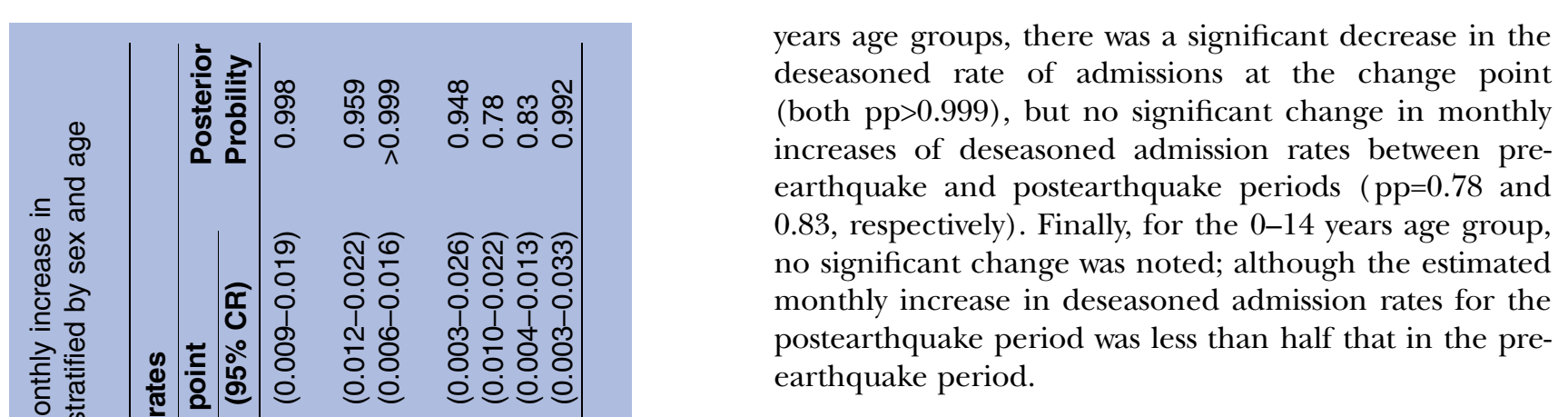

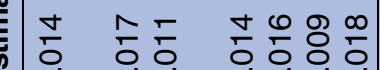
00.0000 สิ $\widehat{0} \widehat{0}$

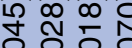
웅ํ 눙요 둥요

\section{DISCUSSION}

Our interpreted time series analysis demonstrated that the rapidly accelerated integrated Canterbury health system transformation strategy after the earthquake significantly lowered the level and the growth rate of acute admissions. These important shifts have significant resource implications. Looking at hospital admissions for December 2014 alone, the difference between projected and fitted rates per 1000 people is 1.31 . Upscaling, this equates to $\sim 676(16.8 \%)$ admissions avoided from 4035 projected for that month. Prior to the earthquake, the community ADMS received 14000 referrals per annum. However, the infrastructure damage and constraints imposed by the earthquake resulted in a rapid escalation of this service, which now receives around 30000 referrals per annum.

The most dramatic reduction in acute admissions growth after the earthquake occurred among those aged $65+$ years. Accelerated population ageing, coupled with the resultant increase in age-related chronic diseases, has been opined as being among the most pressing challenges of all modern health systems worldwide, ${ }^{8} 12$ including New Zealand. ${ }^{10} 27$ As such, Canterbury's integrated health system model, which embodies community inventions including ADMS, CREST, the Medication Management Service (engaging community pharmacists to actively review medications) and the Community Falls Prevention programme, targeted older adults. ${ }^{5}$ Unlike hospital avoidance programmes elsewhere, ${ }^{28}$ this targeting has been successful. For example, among those aged $75+$ years, the Community Falls Prevention programme has been attributed with 1076 fewer ED attendances due to falls, 386 fewer femoral neck fracture operations, 86 fewer deaths 180 days postdischarge, and 25 fewer people in hospital each day as a result of a fracture since February 2012. Should these decreased levels persist, and be generalisable to other health jurisdictions, then the case for the integrated health system model is further enhanced. ${ }^{5} 13$

ED attendance rates were also significantly influenced by the Canterbury health system's whole-system community-focused approach. While the overall ED attendance growth rate did not change between preearthquake and postearthquake periods, this represents a positive and important finding. If a 'business as usual' approach was adopted, growth in the postearthquake 
period could have been expected to accelerate, compensating for the sudden drop. But this did not happen. The sustained rate fall, together with the unchanged monthly postearthquake growth rate, represents a significant resource saving relative to pre-earthquake expectations. However, a significant increase in ED attendances growth was observed in one subgroup, those aged 1534 years; a likely consequence of worker immigration, arriving for the Christchurch rebuilding programme. ${ }^{24}$ It will be of interest to observe this pattern in the future, once the rebuild programme wanes.

\section{Strengths and limitations of this study}

While this study has salient strengths, including the analysis of comprehensive, contemporaneous and accurate hospital data using apposite Bayesian methods, it also has its limitations. In terms of the statistical models, positive autocorrelation was observed between residuals, and some evidence was found to question the normal distribution assumption of ED attendance rates. Such assumption violations may introduce biases into mean and variance estimates; although in this case, such biases are likely to be relatively modest. Sensitivity analysis that removed the most extreme outlying ED attendance rate observation found little change in parameter estimates, and high overlap of respective 95\% CRs (data not show). Population estimates are produced annually by Statistics New Zealand to inform population-based funding for the country's 20 DHBs. However, these estimates lag behind rapid population changes, such as that associated with the Christchurch rebuild workforce, potentially significantly undercounting population or subpopulation numbers. Such undercounting results in rate inflation and may serve to underestimate the true rate reductions observed in the postearthquake period. ED attendances and acute admissions are but two related indicators of Canterbury's whole-system approach, and a fuller suite of indicators should be appraised before more substantial claims of the success of the approach can be made. The sustained decrease in ED attendances and the reduced hospital admission growth rate points to a successful admission avoidance/ acute demand management effort, rather than an unmeasured population effect. However, unmeasured population effects cannot be entirely dismissed. Indeed, the acute admission rates for the ADHB flattened over the 2009-2012 period (figure 2). Although this is likely to have resulted from new and improved ED facilities in neighbouring WDHB, ${ }^{29}$ the northern DHBs working more closely together, ${ }^{29}$ and ADHB's drive to reduce admissions. ${ }^{30}$ Moreover, the baseline acute admission rate was significantly higher in Auckland than Canterbury, although differing data definitions and coding approaches between the DHBs exist, making direct comparisons difficult. The fact that hospitals admission rates decreased most for the target group of older adults further reduces the likelihood of an unmeasured population effect. The possibility that improved pathways could have resulted in increasing direct admissions to the ward without an ED stay was explored, however, little difference was found. Furthermore, it might be opined that the observed attendance and admission decrease may be, at least partially, a lingering consequence of the earthquake rather than the integrated health service changes. Analysis of data from an extended study period, together with further studies directly capturing staff and patient perceptions and behaviour changes would be required to disentangle these effects. Finally, the analyses are defined for the 2008-2014 period, and the findings should not be extrapolated outside this range.

\section{Conclusions}

'Are hospital admissions out of control?'7 There are many reasons why they might be and, if left uncurbed, will only get worse. ${ }^{4}$ Integrated healthcare systems with high quality out-of-hospital care could be part of the solution; $;^{2} 413$ a view championed and implemented within the Canterbury health system. ${ }^{5}$ Using a methodologically novel approach and a rapidly transformed health system, initiated by a devastating earthquake, our findings unequivocally support this position.

\section{Author affiliations}

${ }^{1}$ School of Health Sciences, University of Canterbury, Christchurch, New Zealand

${ }^{2}$ School of Nursing, Midwifery and Social Work, The University of Queensland, Brisbane, Australia

${ }^{3}$ Division of Planning and Funding, Canterbury District Health Board, Christchurch, New Zealand

${ }^{4}$ Canterbury District Health Board, Christchurch, New Zealand

${ }^{5}$ Emergency Department, Christchurch Hospital, Christchurch, New Zealand

${ }^{6}$ Department of Surgery, University of Otago, Christchurch, Christchurch, New Zealand

Acknowledgements The authors thank many people, including members of the public, emergency services, healthcare professionals, police and urban search and rescue personnel who helped the injured people of Canterbury; and the participating DHBs for making available their data.

Contributors PJS conceived the study. All authors finalised the study and contributed to its design. GJH facilitated retrieval of hospital data. PJS conducted the statistical analysis. All authors contributed to data interpretation. PJS and JMD led the manuscript writing with contributions from GJH and MWA. All authors approved the final version. PJS is the guarantor.

Funding This research received no specific grant from any funding agency in the public, commercial or not-for-profit sectors.

Competing interests All authors have completed the Unified Competing Interests form at http://www.icmje.org/coi_disclosure.pdf (available on request from the corresponding author). GJH is an employee of the CDHB and is a member of the Canterbury Clinical Network's Urgent Care Service Level Alliance. JMD received funding from the Emergency Co-ordination Teams and Emergency Care Foundation for medical writing. MWA is an employee of the CDHB, chair of the RHISE Group (Researching the Health /mplications of Seismic Events) and is a trustee of the Emergency Care Foundation. Apart for the salaried positions of GJH and MWA, there were no financial relationships with any organisation that might have an interest in this study; no other relationships or activities that could appear to have influences this work.

Ethics approval The study complied with the ethical standards for human experimentation as established by the Helsinki Declaration 1995 (as revised in 
Edinburgh 2000) and New Zealand's Health and Disability Ethics Committee (HDEC). HDEC defined this study as minimal risk observational research, and it did not require ethics committee review.

Provenance and peer review Not commissioned; externally peer reviewed.

Data sharing statement Other researchers can apply for our data through the CDHB, ADHB and WDHB Planning and Funding Divisions. New Zealand Census data are freely available from Statistics New Zealand. See: http://www. stats.govt.nz/Census/2013-census/data-tables/dhb-tables.aspx.

Open Access This is an Open Access article distributed in accordance with the Creative Commons Attribution Non Commercial (CC BY-NC 4.0) license, which permits others to distribute, remix, adapt, build upon this work noncommercially, and license their derivative works on different terms, provided the original work is properly cited and the use is non-commercial. See: http:// creativecommons.org/licenses/by-nc/4.0/

\section{REFERENCES}

1. Blunt I, Bardsley M, Dixon J. Trends in emergency admissions in England 2004-2009. London: Nuffield Trust, 2010.

2. Lappegard $\varnothing$, Hjortdahl P. Acute admissions to a community hospital-health consequences: a randomized controlled trial in Hallingdal, Norway. BMC Fam Pract 2014;15:198.

3. Hider P, O'Hagan J, Bidwell S, et al. The rise in acute medical admissions. Aust N Z J Med 2000;30:252-60.

4. Gillam S. Rising hospital admissions. BMJ 2010;340:c636.

5. Gullery C, Hamilton G. Towards integrated person-centred healthcare-the Canterbury journey. Future Hosp J 2015;2:111-16.

6. Royal College of Physicians. Hospitals on the edge? The time for action. London: Royal College of Physicians, 2012.

7. Robinson P. Are hospital admissions out of control? Alcester: CHKS, 2010.

8. NHS England. The NHS belongs to the people: a call to action. London: NHS England, 2013.

9. Sandiford $\mathrm{P}$, Zhou L, Salvetto M, et al. Measuring unexplained variation in acute hospital use by patients enrolled with northern New Zealand general practices. J Prim Health Care 2014;6:93-100.

10. Mays N. Reorienting the New Zealand health care system to meet the challenge of long-term conditions in a fiscally constrained environment. http://www.victoria.ac.nz/sacl/about/cpt/publications/pdfs/ Nick-Mays-Revised-Conference-Paper-Jan-2013-website-version.pdf (accessed 7 Sep 2015).

11. Ham C, Imison C, Jennings M. Avoiding hospital admissions: lessons from evidence and experience. London: The King's Fund, 2010.

12. Bayliss EA, Ellis JL, Shoup JA, et al. Effect of continuity of care on hospital utilization for seniors with multiple medical conditions in an integrated health care system. Ann Fam Med 2015;13:123-9.

13. Timmins $\mathrm{N}$, Ham $\mathrm{C}$. The quest for integrated health and social care: a case study in Canterbury, New Zealand. London: The King's Fund, 2013.
14. Steventon A, Bardsley M, Billings J, et al. An evaluation of the impact of community based interventions on hospital use: a case study of eight Partnership for Older People Projects (POPP). London: Nuffield Trust, 2011.

15. McGeoch G, Anderson I, Gibson J, et al. Consensus pathways: evidence into practice. N Z Med J 2015;128:86-96.

16. McGeoch $G$, McGeoch $P$, Shand B. Is HealthPathways effective? An online survey of hospital clinicians, general practitioners and practice nurses. N Z Med J 2015;128:36-46.

17. Johnston D, Standring S, Ronan KR, et al. The 2010/2011 Canterbury earthquakes: context and cause of injury. Nat Hazards 2014;73:627-37.

18. Ardagh MW, Richardson SK, Robinson V, et al. The initial health-system response to the earthquake in Christchurch, New Zealand, in February, 2011. Lancet 2012;379:2109-15.

19. Stevenson JR, Kachali H, Whitman Z, et al. Preliminary observations of the impacts the 22 February Christchurch earthquake had on organisations and the economy: a report from the field. Bull N Z S Earthquake Eng 2011;44:65-76.

20. Carter J. Minister of Civil Defence statement to Parliament that state of national emergency declared. http://www.beehive.govt.nz/speech/ minister-civil-defence-statement-parliament-state-nationalemergency-declared (accessed 6 Jan 2015)

21. Morgan J, Begg A, Beaven S, et al. Monitoring wellbeing during recovery from the 2010-2011 Canterbury earthquakes: the CERA Wellbeing Survey. Int J Disaster Risk Reduction 2015;14(Pt 1):96-103.

22. Canterbury District Health Board. Christchurch Hospital. http://www. cdhb.govt.nz/chc/ (accessed 6 Jan 2015).

23. Canterbury District Health Board. Earthquake update thirteenCanterbury DHB 26 February. http://www.nzdoctor.co.nz/undoctored/2011/february-2011/27/earthquake-update-thirteen-\%E2\% 80\%93-canterbury-dhb-26-february.aspx (accessed 6 Jan 2015).

24. Statistics New Zealand. Population statistics. Dataset: subnational population estimates (Territoral Authority, Area Unit), by age and sex, at 30 June 2006-14 (2013 boundaries). Wellington: Statistics New Zealand, 2015

25. Carlin BP, Gelfand AE, Smith AFM. Hierarchical Bayesian analysis of changepoint problems. App/ Stat 1992;41:389-405.

26. Lunn DJ, Thomas A, Best N, et al. WinBUGS-a Bayesian modelling framework: concepts, structure, and extensibility. Stat Comput 2000;10:325-37.

27. Ministerial Review Group. Meeting the challenge: enhancing sustainability and the patient and consumer experience within the current legislative framework for health and disability service in New Zealand. Wellington: The New Zealand Government, 2009.

28. Steventon A, Bardsley M, Billings J, et al. The role of matched controls in building an evidence base for hospital-avoidance schemes: a retrospective evaluation. Health Serv Res 2012;47:1679-98.

29. Waitemata District Health Board. Annual plan 2010/11. Waitemata: WDHB, 2010.

30. Auckland District Health Board. District annual plan 2010-2011. Auckland: ADHB, 2010. 